\title{
Gas injection for enhanced oil recovery in two-dimensional geology-based physical model of Tahe fractured-vuggy carbonate reservoirs: karst fault system
}

\author{
Zhao-Jie Song ${ }^{1,2,3} \cdot{\text { Meng } \mathrm{Li}^{1,2,3} \cdot \text { Chuang Zhao }}^{1,2,3} \cdot$ Yu-Long Yang ${ }^{1,2,3} \cdot$ Ji-Rui Hou ${ }^{1,2,3}$
}

Received: 20 September 2019 / Published online: 28 January 2020

(c) The Author(s) 2020

\begin{abstract}
Gas injection serves as a main enhanced oil recovery (EOR) method in fractured-vuggy carbonate reservoir, but its effect differs among single wells and multi-well groups because of the diverse fractured-vuggy configuration. Many researchers conducted experiments for the observation of fluid flow and the evaluation of production performance, while most of their physical models were fabricated based on the probability distribution of fractures and caves in the reservoir. In this study, a two-dimensional physical model of the karst fault system was designed and fabricated based on the geological model of TK748 well group in the seventh block of the Tahe Oilfield. The fluid flow and production performance of primary gas flooding were discussed. Gas-assisted gravity flooding was firstly introduced to take full use of gas-oil gravity difference, and its feasibility in the karst fault system was examined. Experimental results showed that primary gas flooding created more flow paths and achieved a remarkable increment of oil recovery compared to water flooding. Gas injection at a lower location was recommended to delay gas breakthrough. Gas-assisted gravity flooding achieved more stable gas-displacing-oil because oil production was at a lower location, and thus, the oil recovery was further enhanced.
\end{abstract}

Keywords Gas injection · Remaining oil $\cdot$ Enhanced oil recovery $\cdot$ Geology-based physical model $\cdot$ Karst fault system

\section{Introduction}

Carbonate hydrocarbon reservoirs are attracting increasing interest due to the fact that they attribute to $52 \%$ of hydrocarbon reserves and $60 \%$ of oil and gas production in the world (Akbar et al. 2000; Deffeyes 2008). In China, marine carbonate reservoirs are widely distributed in 28 basins with a total area of about 1.16 million square miles, a proven oil reserve of 1.5 billion tons and a proven natural gas reserve of 48 trillion cubic feet. Fractured-vuggy carbonate reservoirs

Edited by Yan-Hua Sun

Zhao-Jie Song

songz@cup.edu.cn

1 Unconventional Petroleum Research Institute, China University of Petroleum (Beijing), Beijing 102249, China

2 Beijing Key Laboratory of Greenhouse Gas Sequestration and Oil Exploitation, Beijing 102249, China

3 Basic Theory Laboratory of Improving Oil Recovery in Low Permeability Oilfields, CNPC Tertiary Oil Recovery Key Laboratory, Beijing 102249, China account for $30 \%$ of carbonate reservoirs and are distributed in the Tarim Basin, Qaidam Basin, etc. Tahe Oilfield, located in the Tarim Basin, is a typical fractured-vuggy carbonate reservoir with an original oil in place (OOIP) of billion tons and an annual production of nine million tons ( $\mathrm{Li}$ and Fan 2011; Li 2013). In fractured-vuggy carbonate reservoirs, karst caves and dissolved pores are the main spaces for hydrocarbon storage, and multi-scale densely developed fractures provide the multi-phase fluid flow path. In most case, the oil capacity and fluid flow in the tight carbonate matrix are neglected due to its extremely low permeability and porosity (Li et al. 2016a, b). Because of the random distribution and configuration of fractures, dissolved pores and karst caves, this type of reservoirs exhibits highly severe heterogeneity. During primary production in the Tahe Oilfield, the natural supply of bottom water provides the driving force, and then, water flooding is switched for EOR. The injected water would be channeled through high-conductivity strikes, leading to a sharp rising of water cut and a quick decline in oil production in production wells. And it is also believed that water flooding creates few of new flow 
paths compared to natural bottom water flooding (Hou et al. 2014, 2016).

Since 2013, gas injection, as a main EOR method in carbonate reservoirs (Manrique et al. 2010), has been implemented in the Tahe Oilfield. Up to the end of 2018, the $\mathrm{N}_{2}$ huff n' puff in 490 wells and $\mathrm{N}_{2}$ flooding in 71 multi-well groups have presented a great potential. The oil recovery increment during gas injection accounts for $2.11 \%$. Gas injection enables to create more flow paths and recover the remaining oil (e.g., attic oil at the top of caves and bypassed oil) in that water injection cannot flood (Yuan et al. 2015). However, gas channeling occurs due to the relatively low viscosity of gas and the high conductivity of fractures and partially filled caves. And the effectiveness of gas injection differs greatly among single wells and multi-well groups because of the diverse fractured-vuggy configuration in the reservoir. These phenomena seriously hamper the further application of gas injection in the Tahe Oilfield. Besides, gas-assisted gravity flooding could make full use of gas-oil gravity difference to achieve stable gas-displacing-oil and thus a better sweep efficiency. This EOR method was successfully applied in Cantarell, a complex offshore fractured carbonate field in Mexico, and yielded an optimized oil recovery via reservoir simulation runs (Sanchez et al. 2005). In the Tahe Ordovician reservoir with a thickness of almost $300 \mathrm{~m}$, the oil at the lower part is mainly recovered by water flooding and the oil at the upper part is mostly produced by primary gas flooding. So, gas-assisted gravity flooding is presented with the aim of recovering the remaining oil at the middle part of the reservoir. But its feasibility in the karst fault-controlled reservoir is still unknown. Therefore, it is imperative to investigate fluid flow behavior and gas flooding efficiency within complicated fractured-vuggy structures.

Many physical models were designed, and the relevant in-laboratory experiments were conducted for the observation of fluid flow and the evaluation of oil recovery. CruzHernández et al. (2001) conducted water-displacing-oil experiments within a regular 2-D fractured-vuggy porous (acrylic) cell and calculated the water/oil saturation and oil recovery by taking photographs during the displacement. Kang (2006) designed an optical glass model by etching the fracture and pore network of core slices and illustrated that mesoscale fractures were the main channels for fluid flow. $\mathrm{Li}$ and $\mathrm{Li}$ (2010) fabricated a 3-D fracture-cavity system using PVC material and investigated water-displacingoil behavior in isolated caves. Liu et al. (2012) constructed three typical visual physical models, and then, five types of residual oil were classified after water flooding. Li et al. (2013) simplified the complex fractured-vuggy system as the basic combination of fractures and caves and fabricated single fractured-vuggy organic glass models. The oil/water relative permeability was measured in steady-state flow tests. Wang et al. (2012) drilled the holes and generated fractures in full-diameter core samples to model the real fracturedvuggy system and categorized remaining oil after water flooding tests. Wang et al. (2014) also built a fracturedvuggy cell model for the experimental observation of oil/ water flow behavior under different conditions of injection rate, fractured-vuggy connection and oil viscosity. Jin et al. (2015) carved the fracture network and fracture-cave network on the surface of full-diameter carbonate cores and reviewed polymer gel injection for profile control in different well connection patterns. Yuan et al. (2015) built a 2-D visual fracture-cavity carbonate reservoir model based on the distribution and connection of fractures and caves in the reservoir. The remaining oil was studied after water flooding and $\mathrm{N}_{2}$ flooding potential was evaluated. Rong et al. (2016) developed five typical fracture-cave structure models using white marble. The production curves were obtained and then matched with field data. In turn, field production curves were used to identify the real fracture-cave structures in the reservoir. Song et al. (2016) built simple fractured models, and gas channeling characteristic was identified under different conditions of injection rate, fracture aperture and angle. Lyu et al. (2017) produced a series of physical models of fracture and cave combinations and revealed the mechanisms and governing factors of $\mathrm{N}_{2}$ injection for EOR. Hou et al. (2018) fabricated a 2-D vug network structure model using calcium carbonate powder, quartz sand and epoxy resin. A visualization study was conducted on the flow behavior of oil, water, $\mathrm{N}_{2}$ and foam, and injection parameters were optimized. Table 1 lists the physical models used in previous studies. Through reviewing the previous studies, most of physical models were fabricated based on the probability distribution of fractures and caves in the reservoir, and few of them were described based on the field geological models.

According to outcrop observations, well logging and seismic data analysis, and field practices in the Tahe Oilfield, fractured-vuggy carbonate reservoirs can be categorized into three types based on its karstification, including karst weathering crust system (Wu et al. 2012), karst ancient river system (Lu et al. 2014) and karst fault system (Lu et al. 2015, 2017). Regarding the karst fault system, it is mainly developed in the south part of the Tahe Oilfield. The karstification process has occurred along strike-slip faults. This type of reservoirs is dominated by caves, vugs and fractures that are developed near faults. The faults serve as not only fluid flow paths but also the space for hydrocarbon storage. Shunbei Oilfield, containing 18 strike-slip faulting zones, was first discovered in 2015 as a typical karst fault-controlled reservoir (Jiao 2018). According to the shapes and controlling factors of reservoir spaces, Lu et al. (2017) proposed three types of karst fault-controlled reservoirs including dendritic type, sandwich type and slab type (Fig. 1). The dendritic type was mainly developed along deep-seated and largescale faults and was "Y"- or "V"-shaped. The sandwich type 
Table 1 Fractured-vuggy physical models used in previous studies

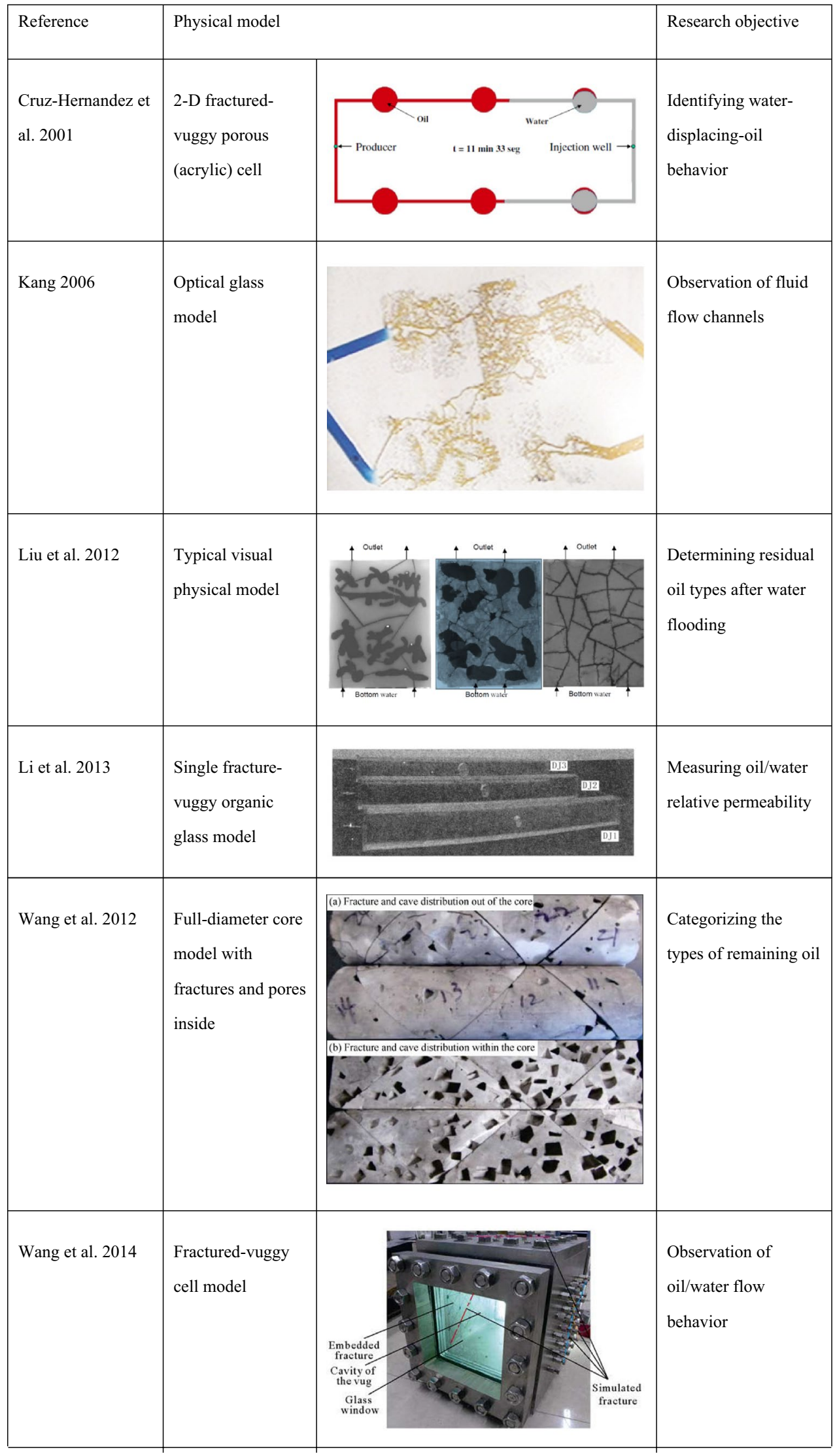


Table 1 (continued)

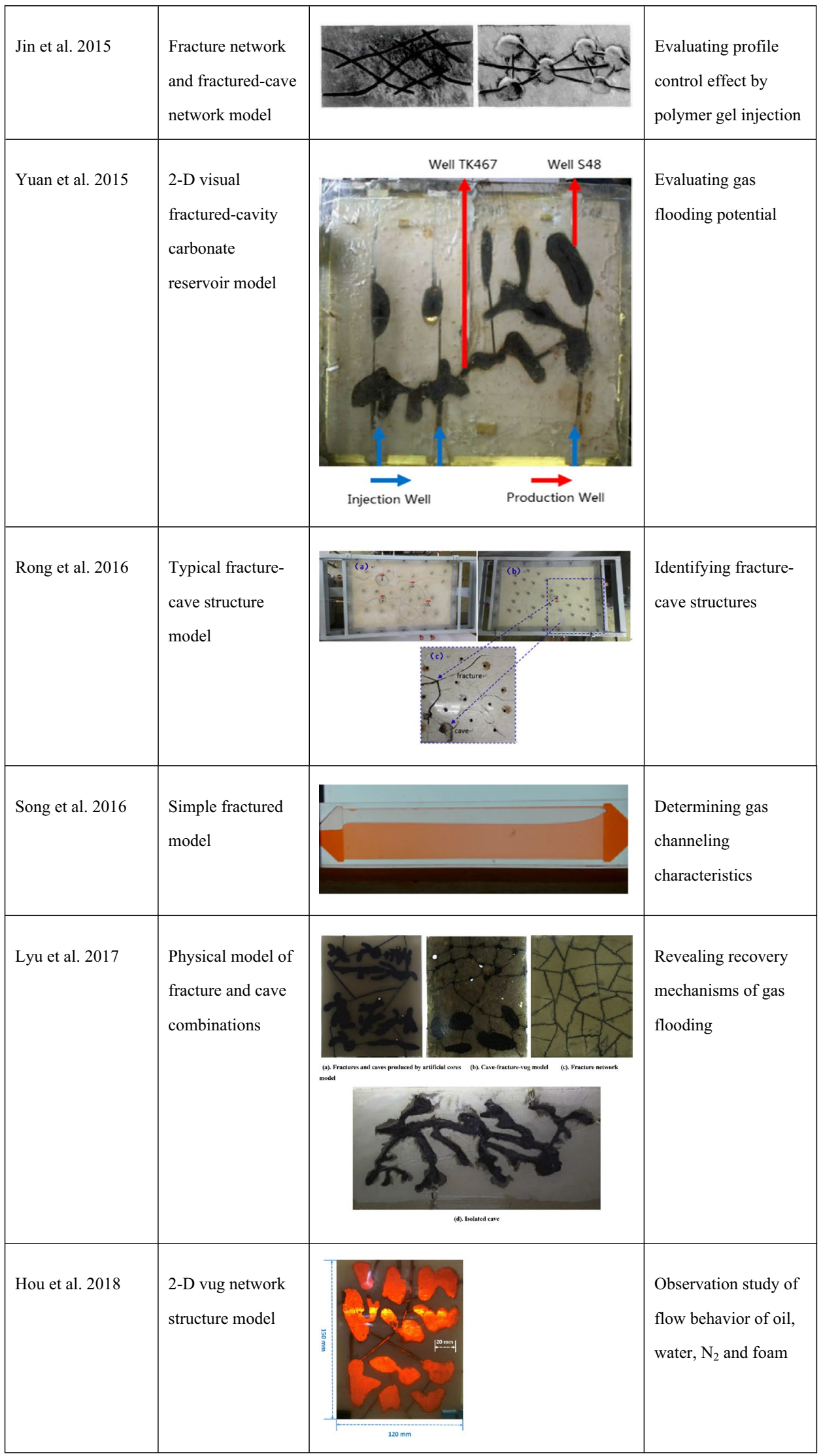



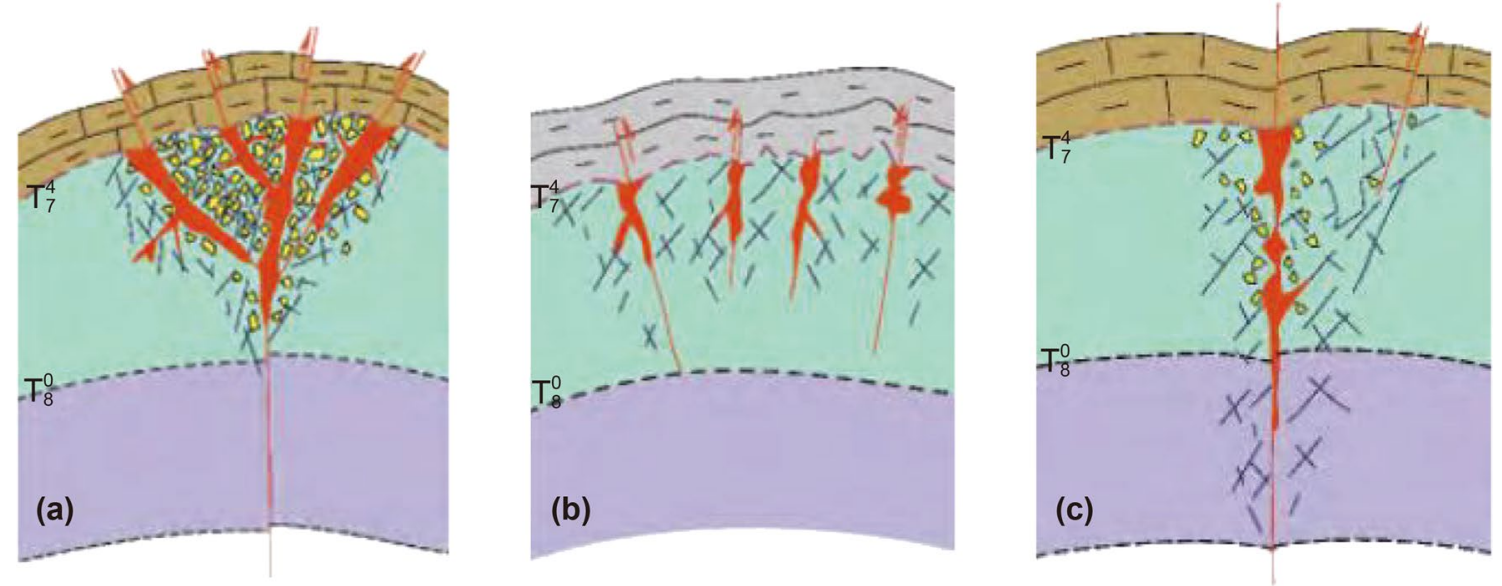

Fig. 1 Three types of karst fault-controlled reservoirs. a Dendritic type. b Sandwich type. c Slab type (Lu et al. 2017)

was controlled by the secondary faults branching from main faults. The slab type presented a single line in geological profile and was controlled by deep faults or small faults. The oil plays of the latter two types were relatively smaller than the dendritic type.

The objectives of this study are to evaluate the effect of gas flooding in the karst fault system and to investigate factors governing gas flooding efficiency. First, a two-dimensional physical model of the karst fault system was designed and fabricated based on the geological model of TK748 well group in the seventh block of the Tahe Oilfield. The geologybased physical model could well represent the real fracturedvuggy system in the reservoir. Second, to be consistent with the field production sequence, gas flooding was performed after bottom water flooding and switched water flooding. Its EOR potential was evaluated, and remaining oil distribution was demonstrated under different conditions of bottom water energy, gas injection location and filling degree of faults. Third, gas-assisted gravity flooding was conducted to study its effect on oil recovery increment.

\section{Experimental section}

\subsection{Physical model of a karst fault system}

The karst fault-controlled reservoirs contain complex fracture-vug structures due to the selective dissolution of karst water and the randomly developed fractures. To better represent the geological features in the reservoir, a physical model in this work was described according to the geological model of TK748 well group in the seventh block of the Tahe Oilfield. Firstly, the geological model was presented in the Petrel E\&P Software, and the two-dimensional geologic profile of the TK7-456-TK748 well group was cut out, as shown in Fig. 2a. This conceptual karst fault system was the slab type. So the experiment in this study was conducted and discussed on this type of karst fault systems. The green zone represented the cross section of the strike-slip fault, and the red zone represented the dissolved caves along the faulting zone. Secondly, four wellbores were designed. Every two adjacent wellbores marked with different numbers (e.g., the red lines marked with numbers 1 and 2 in Fig. 2b) represented the same well in the field. The difference in drilled depth was designed to better model the change of injection or production location. The blue lines in Fig. $2 b$ represented the fractures that connected different cross sections of strike-slip faults. Finally, a rectangular-shaped water tank (blue zone in Fig. 2b) was designed at the bottom of the model to act as the natural bottom water supply. And three wellbores were designed at the bottom of the model to provide bottom water injection. According to the twodimensional diagrammatic sketch, the physical model was carved on a rectangular-shaped acrylic slab and covered by another acrylic slab. The cross section of strike-slip faults was carved with a depth of $0.2 \mathrm{~cm}$, and the dissolved caves were carved with a depth of $1 \mathrm{~cm}$. The fractures were carved with an aperture of $0.5 \mathrm{~mm}$ and a depth of $0.2 \mathrm{~cm}$. And then the two acrylic slabs were fastened by bolts and nuts to ensure no fluid leak through the gap of two slabs. The whole physical model featured with a height of $130 \mathrm{~cm}$, a length of $520 \mathrm{~cm}$ and a thickness of $15 \mathrm{~cm}$. The height/length ratio of the physical model was consistent with the actual ratio of formation thickness and the planar length in the actual geological model. This ensured the geometric similarity of the experimental model, and the gravity effect would not be either exaggerated or reduced. The effective pore volume of the physical model was $119.4 \mathrm{~mL}$. And the effective volume of strike-slip faults and dissolved caves accounted for about $98 \%$ in the physical model. This was consistent with the fact 

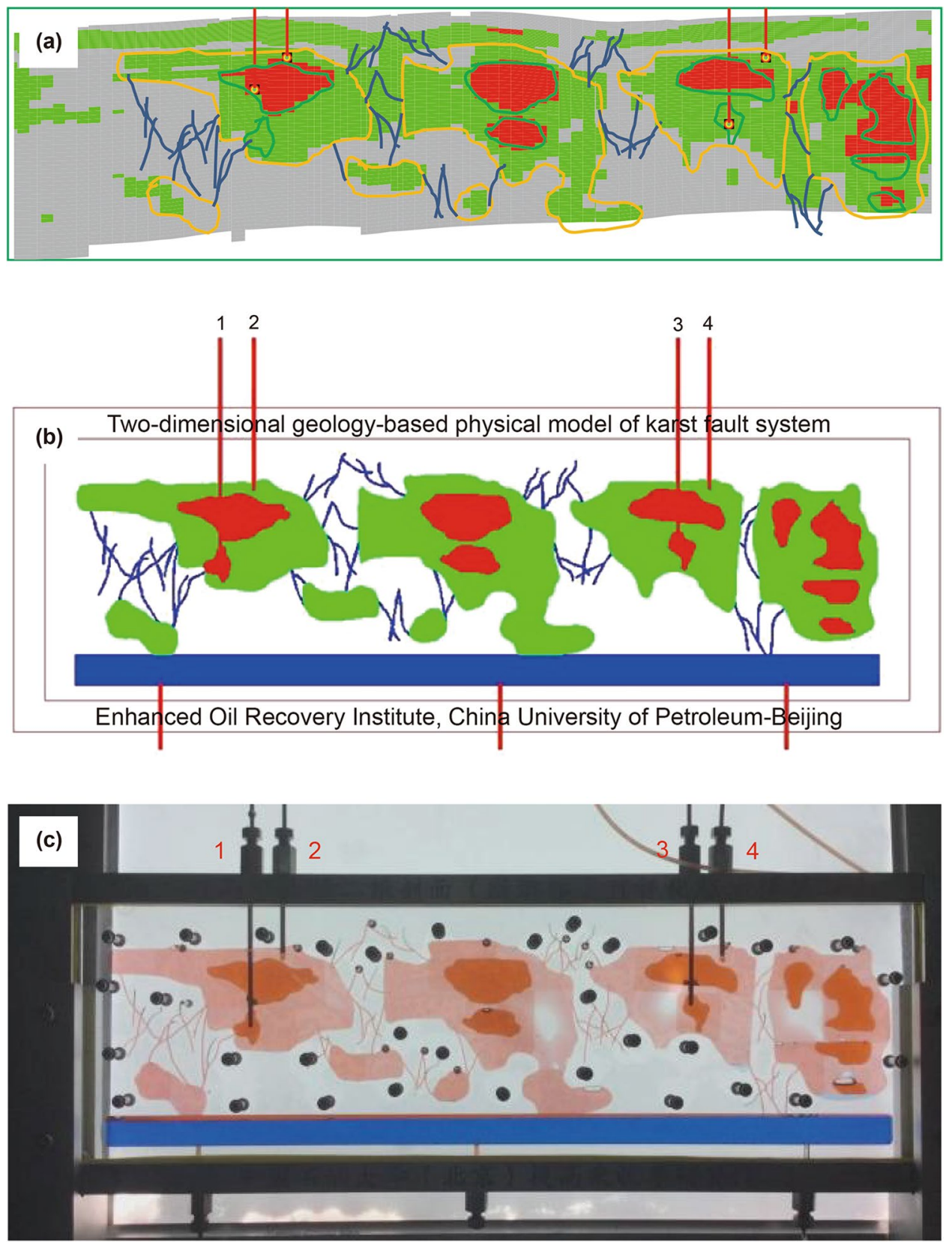

Fig. 2 Design of a two-dimensional physical model of karst fault-controlled reservoir. a Two-dimensional geologic profile of TK7-456-TK748 well group. b Diagrammatic sketch of the geology-based physical model. $\mathbf{c}$ Photograph of geology-based physical model

that caves contributed more than $95 \%$ of oil production in fractured-vuggy carbonate reservoirs (Li et al. 2016a).

\subsection{Experimental fluid}

The simulated oil used in the experiments was prepared by mixing paraffin oil and aviation kerosene with a volume ratio of 20:1. The mixed oil had a viscosity of $23.8 \mathrm{mPa} \cdot \mathrm{s}$ under experimental conditions, which is consistent with the crude oil viscosity under reservoir conditions. This ensured the dynamic similarity of this experimental study. The formation water used had a density of $1.032 \mathrm{~g} / \mathrm{mL}$ and a salinity of $22 \times 10^{4} \mathrm{mg} / \mathrm{L}$. The injected gas was nitrogen with a purity of $99.99 \%$ and a viscosity of $0.0178 \mathrm{mPa} \cdot \mathrm{s}$ under standard conditions. The simulated oil and formation water were dyed with Sudan red and methylene blue, respectively, to obtain a better observation of the oil/water/ gas distributions during the experiments. The experiments were carried out under room temperature and pressure conditions. 


\subsection{Experimental setup}

The experimental setup mainly consisted of a power driving system, several high-pressure accumulators, the 2-D geology-based physical model and a liquid collector. Two syringe pumps with a working pressure range of 0-30 MPa and a flow rate range of $0.01-10 \mathrm{~mL} / \mathrm{min}$ provided the driving force of simulated oil and formation water stored in highpressure accumulators. A high-pressure gas cylinder connected with a gas flow meter (SevenStar Electronics, Beijing, China) enabled the injection of nitrogen at a designed flow rate. The effluent of oil and water was collected and measured using a liquid collector during the experiments. The fluid flow behavior in the 2-D physical model was observed and recorded with a Logitech Pro C922 video camera. The diagram of gas flooding experimental setup is shown in Fig. 3.

\subsection{Experimental scenarios and procedures}

\subsubsection{Experimental scenarios}

The workflow of this study was divided into two parts: (1) Primary gas flooding experiments were performed to investigate the remaining oil distribution and its governing factors. (2) Gas-assisted gravity flooding experiments were carried out subsequently to study whether this method could effectively recover the remaining oil after primary gas flooding.

During the primary gas flooding experiments, bottom water flooding, switched water flooding and primary gas flooding experiments were carried out in turn in the twodimensional physical model of the karst fault system. The distribution of remaining oil after gas injection was analyzed. In order to study the governing factors of remaining oil, several experimental scenarios are designed in Table 2

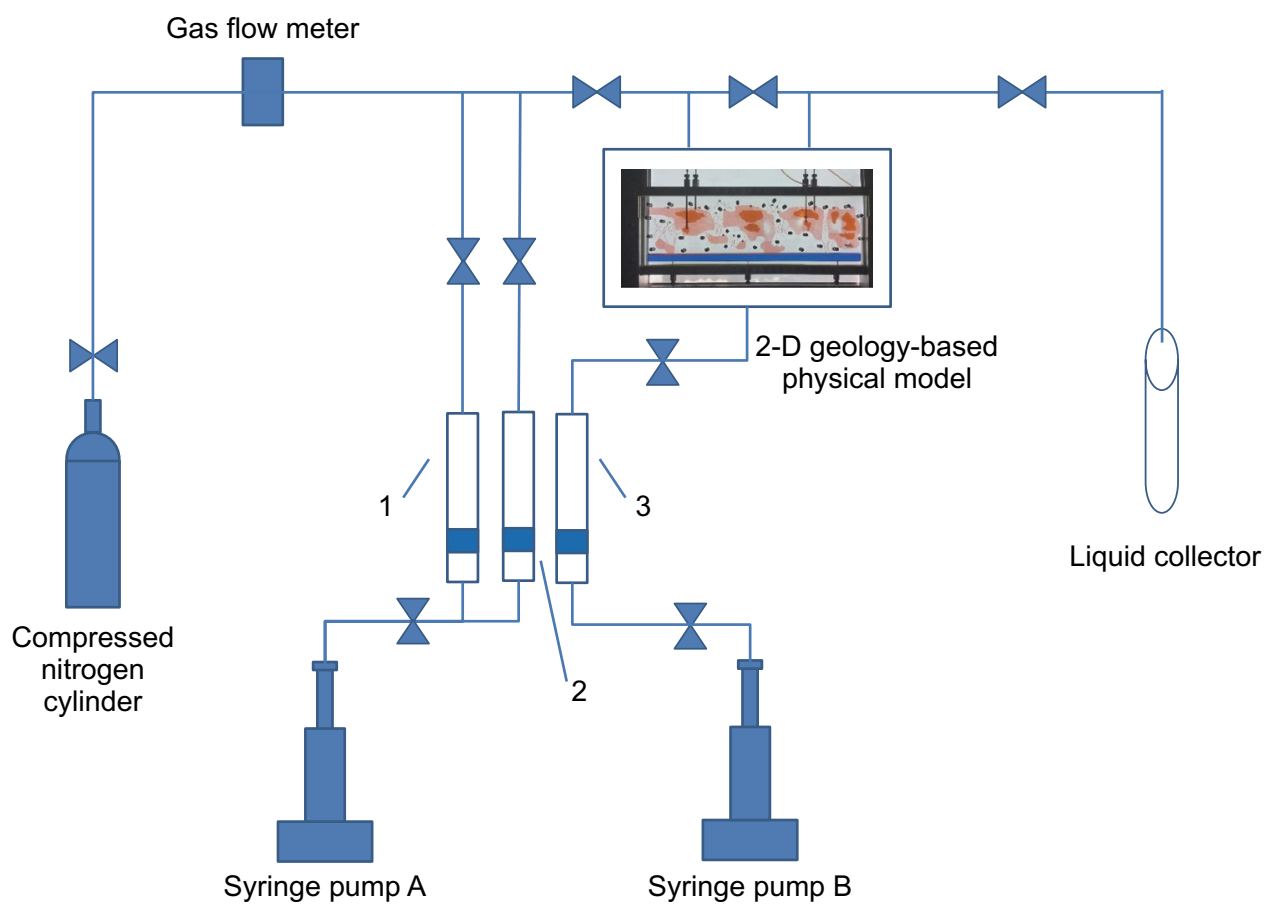

Fig. 3 Schematic diagram of the experimental setup for gas flooding. High-pressure accumulators 1, 2 and 3 are, respectively, filled with simulated oil, formation water for switched water injection and formation water for bottom water supply

Table 2 Experimental scenarios of primary gas flooding

\begin{tabular}{|c|c|c|c|c|c|}
\hline \multirow[t]{2}{*}{ Scenario } & \multirow{2}{*}{$\begin{array}{l}\text { Bottom water } \\
\text { injection rate, } \mathrm{mL} / \\
\text { min }\end{array}$} & \multirow{2}{*}{$\begin{array}{l}\text { Switched water } \\
\text { injection rate, } \mathrm{mL} / \\
\text { min }\end{array}$} & \multicolumn{2}{|c|}{ Primary gas flooding } & \multirow{2}{*}{$\begin{array}{l}\text { Filling } \\
\text { degree of } \\
\text { faults }\end{array}$} \\
\hline & & & $\begin{array}{l}\text { Gas injection } \\
\text { rate, } \mathrm{mL} / \mathrm{min}\end{array}$ & Location of injection well and production well & \\
\hline A & 3 & 3 & 3 & Low-location injection and high-location production (LIHP) & Unfilled \\
\hline $\mathrm{B}$ & 1 & 1 & 3 & Low-location injection and high-location production (LIHP) & Unfilled \\
\hline $\mathrm{C}$ & 3 & 3 & 3 & High-location injection and high-location production (HIHP) & Unfilled \\
\hline $\mathrm{D}$ & 3 & 3 & 3 & Low-location injection and high-location production (LIHP) & $70 \%$ \\
\hline
\end{tabular}


under different conditions of bottom water energy, gas injection location and filling degree of faults. It should be noted that bottom water was consistently supplied at the designed flow rate during switched water flooding and primary gas flooding. Besides, in this study the injection rate of $1 \mathrm{~mL} /$ min exhibited a flux velocity of about $3 \mathrm{~cm} / \mathrm{min}$, i.e., $43.2 \mathrm{~m} /$ day. This was consistent with the practical flow velocity of 30-150 m/day in fractured-vuggy carbonate reservoirs (Wang et al. 2012), which ensured the kinematic similarity of this experimental study.

In the physical model, every two wellbores were designed to represent one well with different injection or production locations in the field. Through producing oil at a lower location, gas-assisted gravity flooding was carried out after primary gas flooding to achieve more stable gas-displacing-oil with the aid of gas-oil gravity difference. The oil-displacement efficiency and its governing factors were discussed by performing a series of experiments. The specific experimental scenarios are designed in Table 3.

\subsubsection{Experimental procedures}

The experiments were performed as follows:

(1) The simulated oil was injected from the bottom of the model to saturate the whole physical model and the volume of saturated oil was recorded. The rectangular-shaped water tank (blue zone in Fig. 2b) in the bottom of the model was then saturated with the formation water, and the injected volume was recorded simultaneously. The effective pore volume of the model is the difference between the volume of saturated oil and the volume of saturated formation water.

(2) The formation water was injected from the bottom of the model to conduct bottom water flooding. The relatively deeper wellbores (i.e., the wellbores 1 and 3 in
Fig. 2) were opened for oil production, and the other wellbores (i.e., the wellbores 2 and 4 in Fig. 2) were closed. The oil and water production rates were recorded. The well (e.g., the wellbore 1 in this experiment) was shut in when its water cut reached $98 \%$, and then, the bottom water flooding experiment was terminated.

(3) The waterflooded well (i.e., the wellbore 1) was used as water injection well, and the other well (i.e., the wellbore 3) continued to serve as the production well. The switched water flooding was initiated at the designed flow rate. The oil and water production rates were recorded, and the switched water flooding experiment was terminated when the water cut of production well (i.e., the wellbore 3) reached $98 \%$.

(4) The water injection well (i.e., the wellbore 1 or 2) was converted as gas injection well. In the oilfield practice, the production location of production wells would move upward during gas flooding. The reason is that the oil-water contact had reached the previous production location at the end of switched water flooding. Therefore, in this study the relatively shallower wellbore of the other well (i.e., the wellbore 4) was opened as the production well to conduct the primary gas injection experiment. The oil and water production rates were recorded. The primary gas flooding experiment was terminated when gas breakthrough occurred, i.e., no oil was produced from the production well (i.e., the wellbore 4).

(5) The relatively shallower wellbore (i.e., the wellbore 2) was shut in, and the deeper wellbore (i.e., the wellbore 1) of the previous injection well in step (4) was opened as the production well. And the deeper or shallower wellbore of the other well (i.e., the wellbore 3 or 4 ) was opened as gas injection well according to the scenarios in Table 3. Gas-assisted gravity flooding was performed, and the water and oil production rates were recorded. The production well was shut

Table 3 Experimental scenarios of gas-assisted gravity flooding

\begin{tabular}{|c|c|c|c|c|c|c|c|}
\hline \multirow[t]{2}{*}{ Scenario } & \multirow{2}{*}{$\begin{array}{l}\text { Bottom water } \\
\text { injection rate, } \mathrm{mL} / \\
\text { min }\end{array}$} & \multirow{2}{*}{$\begin{array}{l}\text { Switched water } \\
\text { injection rate, } \mathrm{mL} / \\
\text { min }\end{array}$} & \multicolumn{2}{|c|}{ Primary gas flooding } & \multicolumn{2}{|c|}{ Gas-assisted gravity flooding } & \multirow{2}{*}{$\begin{array}{l}\text { Filling } \\
\text { degree of } \\
\text { faults }\end{array}$} \\
\hline & & & $\begin{array}{l}\text { Gas injection } \\
\text { rate, } \mathrm{mL} / \mathrm{min}\end{array}$ & $\begin{array}{l}\text { Location of injection } \\
\text { well and production } \\
\text { well }\end{array}$ & $\begin{array}{l}\text { Gas injection } \\
\text { rate, } \mathrm{mL} / \mathrm{min}\end{array}$ & $\begin{array}{l}\text { Location of injection } \\
\text { well and production } \\
\text { well }\end{array}$ & \\
\hline $\mathrm{E}$ & 3 & 3 & 3 & $\begin{array}{l}\text { Low-location injection } \\
\text { and high-location } \\
\text { production (LIHP) }\end{array}$ & 3 & $\begin{array}{l}\text { High-location injection } \\
\text { and low-location } \\
\text { production (HILP) }\end{array}$ & Unfilled \\
\hline $\mathrm{F}$ & 1 & 1 & 3 & $\begin{array}{l}\text { Low-location injection } \\
\text { and high-location } \\
\text { production (LIHP) }\end{array}$ & 3 & $\begin{array}{l}\text { High-location injection } \\
\text { and low-location } \\
\text { production (HILP) }\end{array}$ & Unfilled \\
\hline $\mathrm{G}$ & 3 & 3 & 3 & $\begin{array}{l}\text { Low-location injection } \\
\text { and high-location } \\
\text { production (LIHP) }\end{array}$ & 3 & $\begin{array}{l}\text { Low-location injection } \\
\text { and low-location } \\
\text { production (LILP) }\end{array}$ & Unfilled \\
\hline $\mathrm{H}$ & 3 & 3 & 3 & $\begin{array}{l}\text { Low-location injection } \\
\text { and high-location } \\
\text { production (LIHP) }\end{array}$ & 3 & $\begin{array}{l}\text { High-location injection } \\
\text { and low-location } \\
\text { production (HILP) }\end{array}$ & $70 \%$ \\
\hline
\end{tabular}


in when gas breakthrough occurred, and the gas-assisted gravity flooding experiment was terminated.

\section{Results and discussion}

\subsection{Analysis of primary gas flooding in the karst fault system}

\subsubsection{Oil-displacement characteristics of primary gas flooding}

Figures 4 and 5 depict the fluid flow and production performance during bottom water flooding, switched water flooding and primary gas flooding of Scenario A. The red part, blue part and colorless part in the model represented oil, water and gas, respectively. The bottom water stably displaced oil at the bottom water flooding stage and water channeling occurred in the wellbore 1 due to its relatively

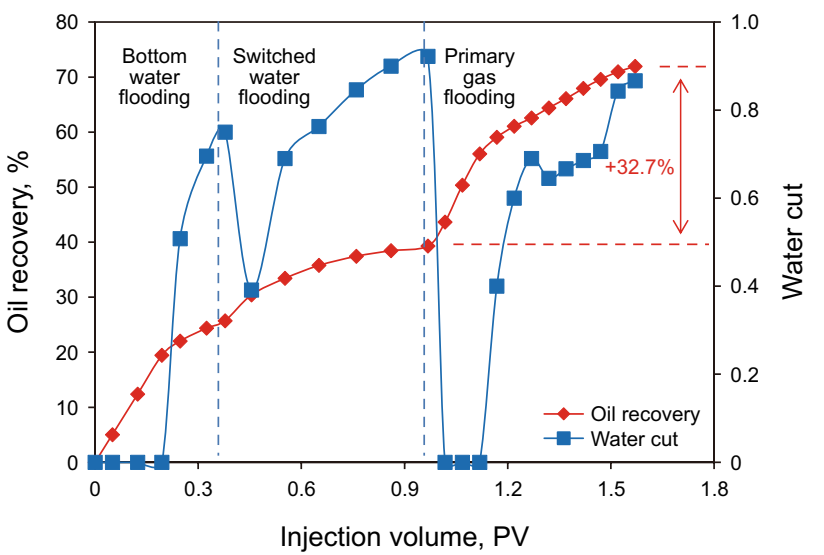

Fig. 5 Production performance of bottom water flooding, switched water flooding and primary gas flooding of Scenario A
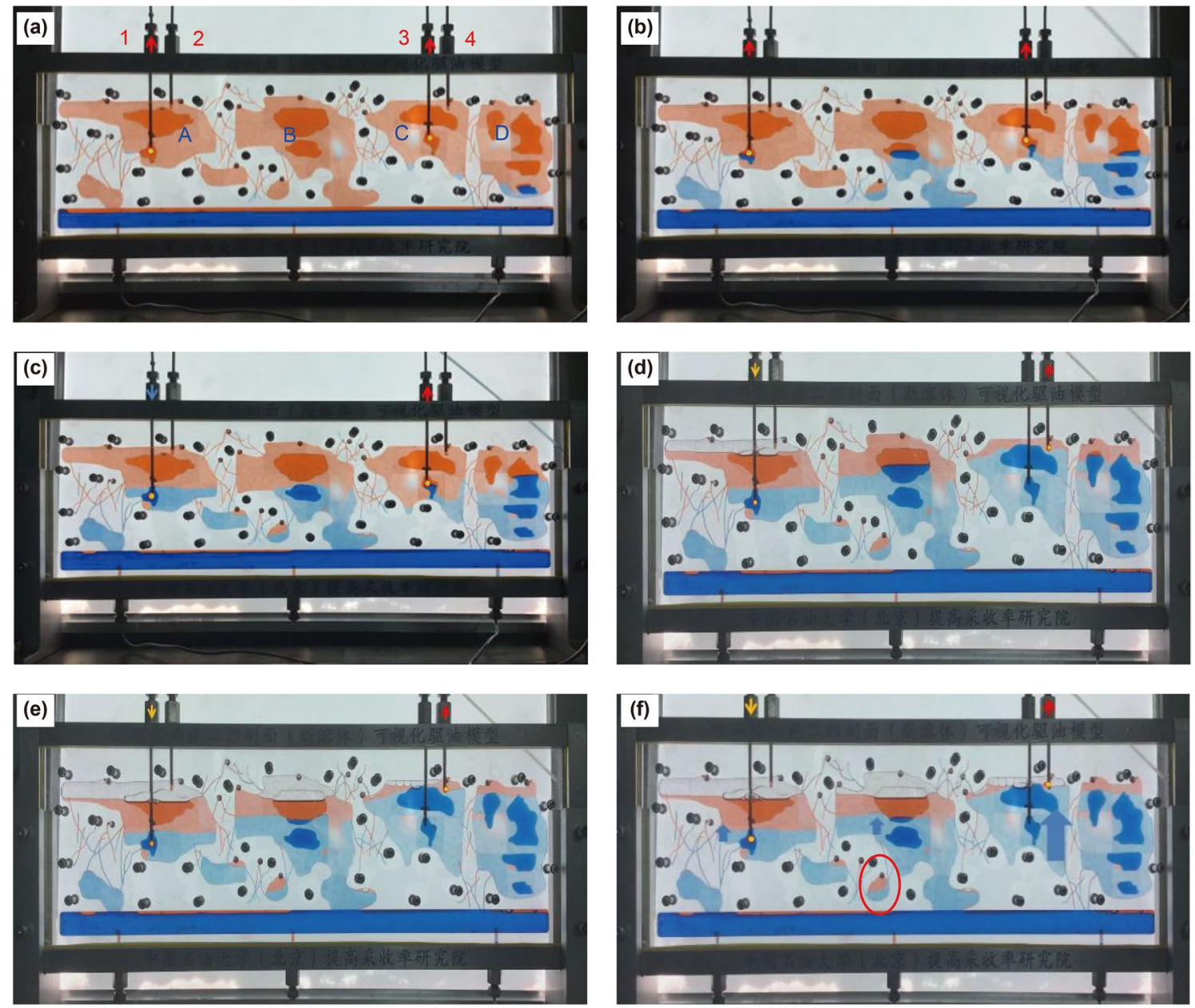

Fig. 4 Fluid distributions at different stages of Scenario A. a The end of oil saturation. b The end of bottom water flooding. c The end of switched water flooding. $\mathbf{d}$ The middle stage of primary gas flooding. e The late stage of primary gas flooding. $\mathbf{f}$ The end of primary gas flooding 
lower production location compared to the wellbore 3 . Then, the wellbore 1 was switched for water injection. According to the comparison of Figs. 4 and 5, few of new flow paths were formed at the switched water flooding stage, and the production wellbore 3 was quickly waterflooded under the co-effect of switched water injection and bottom water drive. At the primary gas flooding stage, the injected gas first moved upward to form a secondary gas cap. The oil at the upper part of the injection well was displaced downward. Then with the co-effect of gas injection and bottom water drive (Qu et al. 2018), the oil in Fault A was displaced laterally to Fault B through the fractures between the two faults. And then, the similar process of fluid flow occurred in Fault $\mathrm{B}$, and the oil was displaced laterally to Fault $\mathrm{C}$ and finally produced from the production well. The oil-displacement process in the fault was similar to that in a single cave $(\mathrm{Qu}$ et al. 2018). At the beginning of primary gas flooding, the oil in the near-production-well area of Fault $\mathrm{C}$ was mainly recovered with the driving force of bottom water, because no gas flowed into Fault $\mathrm{C}$. The water cut in this period was lowered to zero, as depicted in Fig. 5. Finally, gas breakthrough occurred in the production well and primary gas flooding was terminated. Comparing with water flooding, more of fluid flow paths were formed, i.e., the sweep efficiency was improved and primary gas flooding presented a remarkable incremental oil recovery of $32.7 \%$.

After the primary gas flooding, the remaining oil distribution in the karst fault-controlled reservoir is mainly controlled by the developed faults. It can be seen in Fig. $4 \mathrm{f}$ that the remaining oil was accumulated in the area near the injection well and the interwell area. The amount of remaining oil increased gradually from the production well to the injection well. In a single fault, the remaining oil was accumulated in the middle part, which was similar to the remaining oil distribution in a single cave (Qu et al. 2018). In addition, there was some remaining oil in the bypass zone (the red cycle in Fig. 4f) caused by the connected fractures.

\subsubsection{Governing factors of primary gas flooding}

Effect of bottom water energy Figure 6 illustrates the fluid distribution at the end of primary gas flooding of Scenario B. In Scenario B, the gas injection rate was $3 \mathrm{~mL} / \mathrm{min}$ and the bottom water injection rate was $1 \mathrm{~mL} / \mathrm{min}$. So, the energy of bottom water drive was relatively weaker than that in Scenario A. According to the comparison of Figs. $4 \mathrm{f}$ and 6 , the distribution of remaining oil was similar, which could be attributed to the relatively simple fracture-cavity structure in the karst fault system. However, in Scenario B the injected gas inhibited the bottom water drive in the area near the injection well and the interwell area. Thus, the oil-water contact lowered rapidly and the remaining oil in the area near the injection well increased significantly. The oil

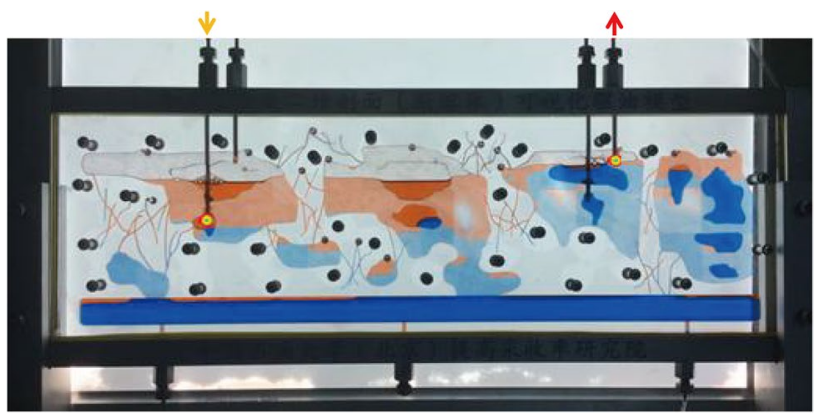

Fig. 6 Fluid distribution at the end of primary gas flooding when bottom water injection was $1 \mathrm{~mL} / \mathrm{min}$ in Scenario B

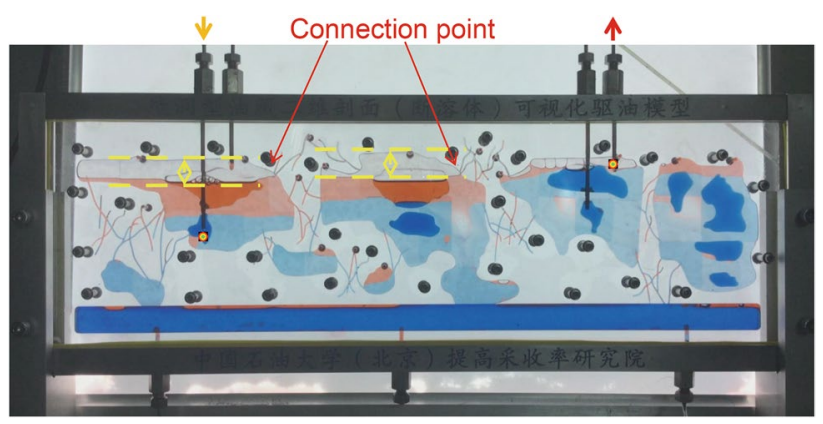

Fig. 7 Effect of fracture development on fluid distribution at the end of primary gas flooding in Scenario A

recovery was lowered by $11.31 \%$. So, the energy imbalance of gas injection and bottom water drive was not conducive to oil production in karst fault systems.

Effect of fracture development Figure 7 demonstrates the effect of fracture development on primary gas flooding and remaining oil distribution. In the karst fault system, remaining oil distribution was mainly controlled by the strike-slip faults. The impact of developed fractures was less significant compared to that in the karst weathering crust system. However, the fractures that connected two faults determined the amount of gas that could be stored and the amount of oil that could be displaced in a single fault. The injected gas was firstly accumulated at the upper part of the fault and would flow to the adjacent fault when gas-oil contact reached the connection point of the fractures.

Effect of gas injection location Figure 8 depicts the effect of gas injection location on fluid distribution at the end of primary gas flooding. Under the HIHP condition in Scenario $\mathrm{C}$, the injected gas was much easier to move laterally. Therefore, the lateral displacement velocity of the injected gas was relatively higher, and the co-effect period of gas injection and bottom water drive was shortened. So, the remaining oil in the near-production-well area was relatively more comparing with that under the LIHP condition in Scenario A (Fig. 4f). 


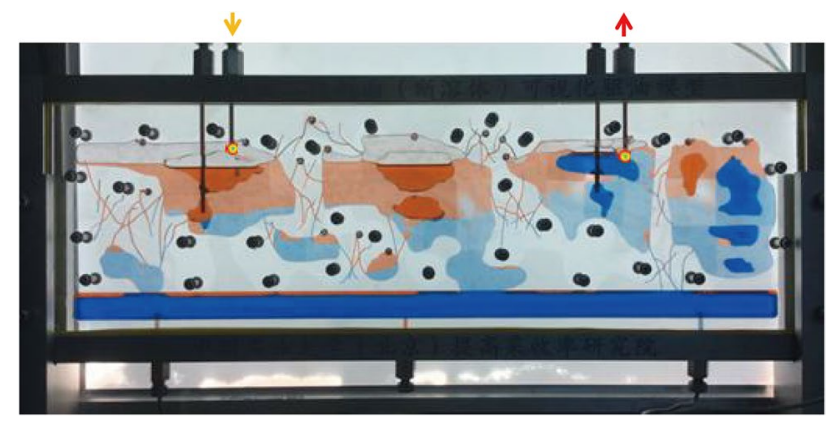

Fig. 8 Fluid distribution at the end of primary gas flooding under the HIHP condition in Scenario C

Effect of filling degree of faults In fractured-vuggy carbonate reservoirs, many storage spaces including dissolved caves, vugs and faults are fully or partially filled due to the collapse of cave wall in the process of reservoir forming (Xu et al. 2010; Chen et al. 2013). The filling degree of faults would influence the fluid flow inside and gas flooding efficiency (Wang et al. 2019). Scenario $\mathrm{D}$ was designed and $70 \%$ of pore volume was filled with glass beads in the model, and the effect of fault filling was discussed by comparing with Scenario A. Figures 9 and 10 present the fluid flow and oil recovery of primary gas flooding in Scenario D. As shown in Fig. 4f, the gas-oil contact and oil-water contact were relatively even in a single fault when the model was unfilled. However, in Fig. 9, the gas-oil contact was not flat even in a single fault when the filling degree of faults was $70 \%$. That means not all the oil was recovered in the gas-swept zone, and the area containing remaining oil became larger. Besides, the filling in the model increased the fluid flow resistance. The injected gas would not only flow upward. The increased flow resistance diverted the fluid to create more paths, and the sweep efficiency was enhanced. Thus, the production period was much longer and the oil recovery was $8.72 \%$ higher, as shown in Fig. 10.

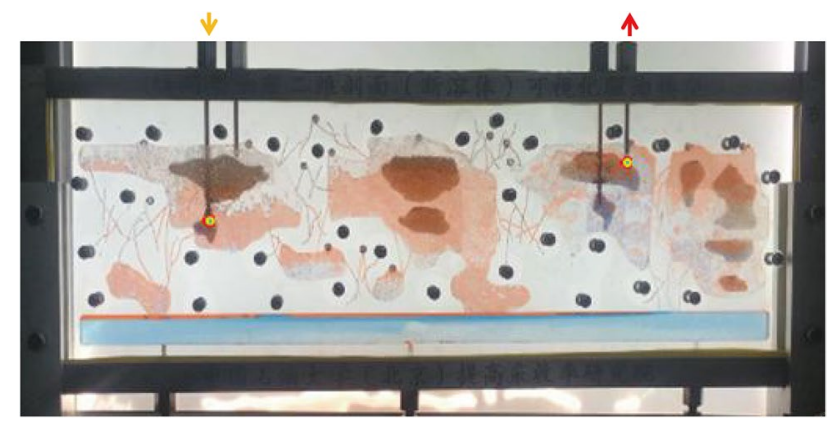

Fig. 9 Fluid distribution at the end of primary gas flooding when $70 \%$ of pore volume was filled in Scenario D

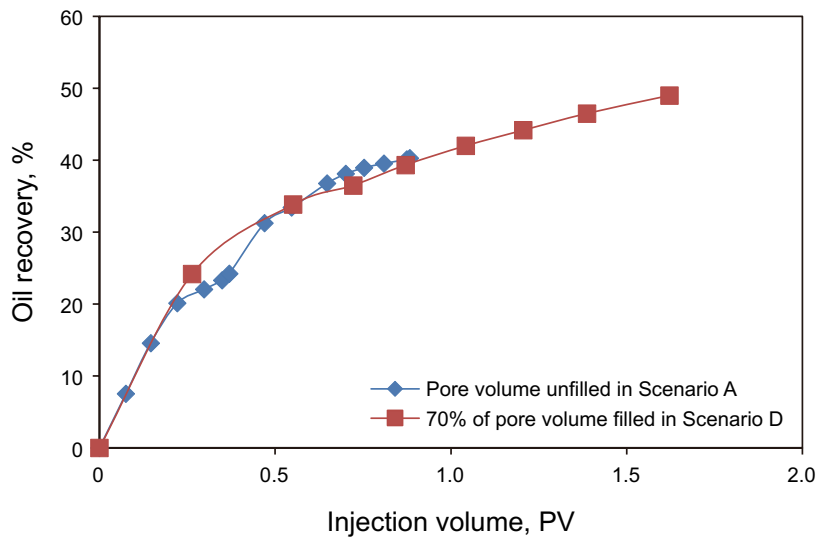

Fig. 10 Comparison of oil recovery of primary gas flooding when the pore volume was unfilled in Scenario A and $70 \%$ of pore volume was filled in Scenario D

\subsection{Analysis of gas-assisted gravity flooding in the karst fault system}

\subsubsection{Oil-displacement characteristics of gas-assisted gravity flooding}

As mentioned above, much oil was remained in the area near the injection well and the interwell area after primary gas flooding. Gas-assisted gravity flooding was proposed here to recover this type of remaining oil. Figures 11 and 12 illustrate the fluid flow and production performance during gas-assisted gravity flooding of Scenario E. The previous injection well (i.e., the wellbore 1) and production well (i.e., the wellbore 4) in Fig. 11a were converted as the production well and the injection well at the stage of gas-assisted gravity flooding, respectively. The objectives were to make full use of oil-gas gravity difference and to recover the remaining oil after primary gas flooding. As shown in Fig. 11, the energy increase associated with gas injection from the wellbore 4 would suppress bottom water drive in Fault C. So, bottom water drive mainly took effect in Fault A, and the liquid was firstly produced from the wellbore 1 with a water cut of $100 \%$, as shown in Fig. 12. As the injected gas moved and accumulated in Faults A and $\mathrm{B}$, the remaining oil was recovered with the co-effect of gas injection and bottom water drive. Finally, almost all the oil remained in the area near the previous injection well (i.e., the remaining oil in Fault A) and a part of the remaining oil in the interwell area (i.e., the remaining oil in Fault B) was recovered during gas-assisted gravity flooding. The incremental oil recovery of $11.7 \%$ also proved its great EOR potential, as shown in Fig. 12. 

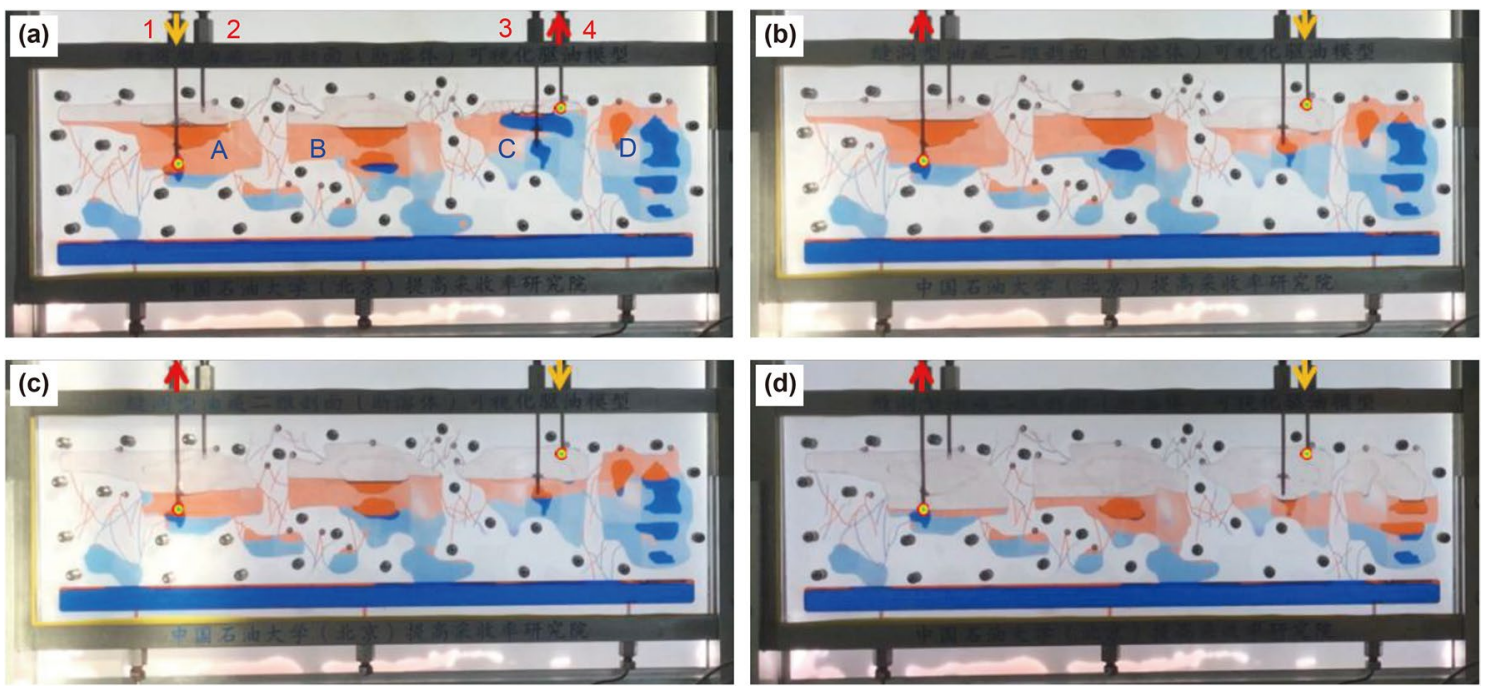

Fig. 11 Fluid distributions at $\mathbf{a}$ the end of primary gas flooding, $\mathbf{b}$ the middle stage, $\mathbf{c}$ the late stage and $\mathbf{d}$ the end of gas-assisted gravity flooding of Scenario E

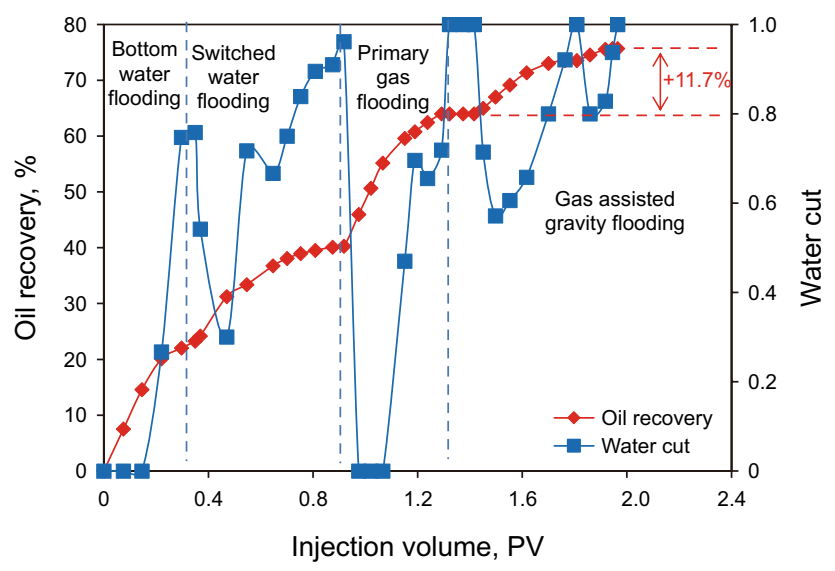

Fig. 12 Production performance of bottom water flooding, switched water flooding, primary gas flooding and gas-assisted gravity flooding in Scenario E

\subsubsection{Governing factors of gas-assisted gravity flooding}

Effect of bottom water energy Figure 13 illustrates the fluid distribution at the end of gas-assisted gravity flooding when the bottom water injection rate was $1 \mathrm{~mL} / \mathrm{min}$ and the gas injection rate was $3 \mathrm{~mL} / \mathrm{min}$ in Scenario $\mathrm{F}$. In Scenario E, the balanced energy of gas injection and bottom water drive resulted in the remaining oil left in the same depth with the production location of the wellbore 1, as shown in Fig. 11d. However, in Scenario F, the bottom water was suppressed by the injected gas, and some oil was also displaced downward. At the end, the remaining oil was concentrated in a deeper area than the production location. The oil recovery was lowered by $5.03 \%$.

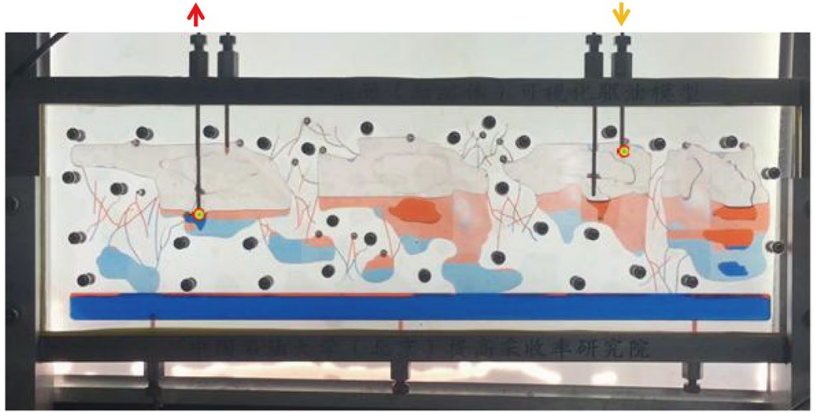

Fig. 13 Fluid distribution at the end of gas-assisted gravity flooding when the bottom water injection was $1 \mathrm{~mL} / \mathrm{min}$ in Scenario $\mathrm{F}$

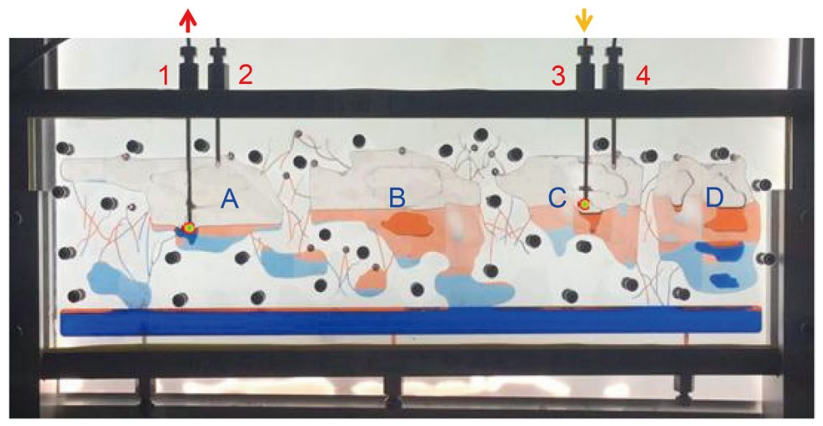

Fig. 14 Fluid distribution at the end of gas-assisted gravity under the LILP condition in Scenario G

Effect of gas injection location Figure 14 demonstrates the fluid distribution at the end of gas-assisted gravity flooding under the LILP condition in Scenario G, and Fig. 15 compares its oil recovery with that under the HILP condition in Scenario E. According to the comparison of Figs. 14 and 


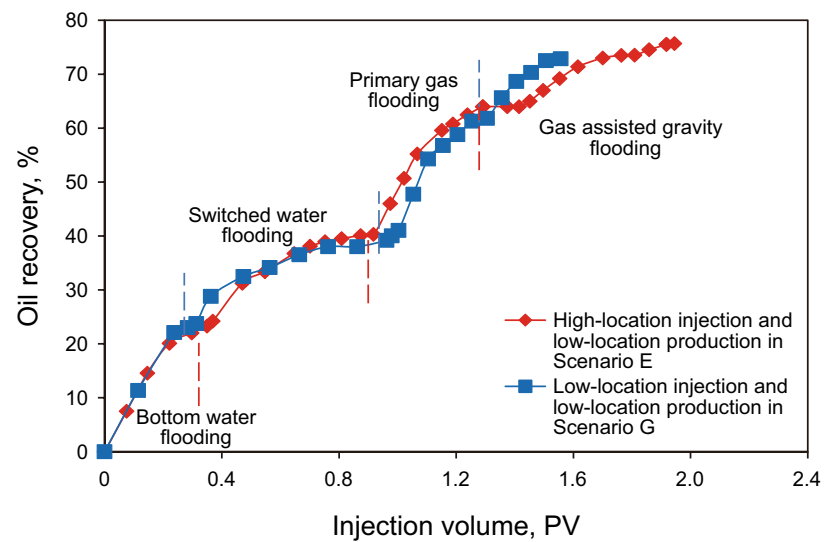

Fig. 15 Comparison of oil recovery of gas-assisted gravity flooding under the conditions of HILP in Scenario E and LILP in Scenario G

11d, the distribution pattern of remaining oil was almost the same. However, the remaining oil in Scenario G was left in the relatively lower area in the physical model. That could be attributed to the fact that gas injection at a lower location (i.e., the wellbore 3) suppressed bottom water drive more effectively in Fault $\mathrm{C}$. The effect of bottom water drive was enhanced, leading to an earlier water breakthrough in the production well. As shown in Fig. 15, the oil-displacement period of gas-assisted gravity flooding was shortened and its oil recovery was $2.84 \%$ lower when gas was injected at the low location (i.e., the wellbore 3) in Scenario G.

Effect of filling degree of faults Figure 16 presents the fluid distribution at the end of gas-assisted gravity flooding when $70 \%$ of pore volume was filled in Scenario $\mathrm{H}$, and Fig. 17 compares its oil recovery with that of Scenario E (i.e., the pore volume was unfilled). According to the comparison of Figs. 11 and 16, the injected gas could flow from the gas injection well to the production well through the upper part of the model when the pore volume was unfilled. And the fluid interface was relatively even during the gasassisted gravity flooding experiment. When $70 \%$ of pore

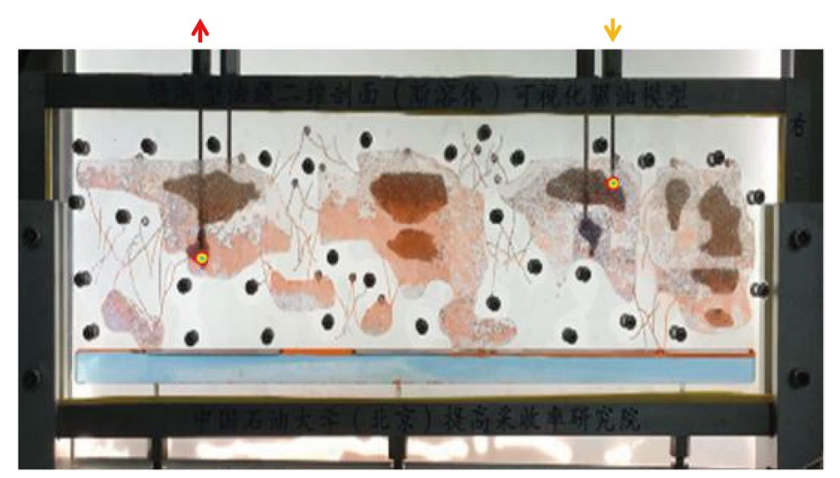

Fig. 16 Fluid distribution at the end of gas-assisted gravity flooding when $70 \%$ of pore volume was filled in Scenario $\mathrm{H}$

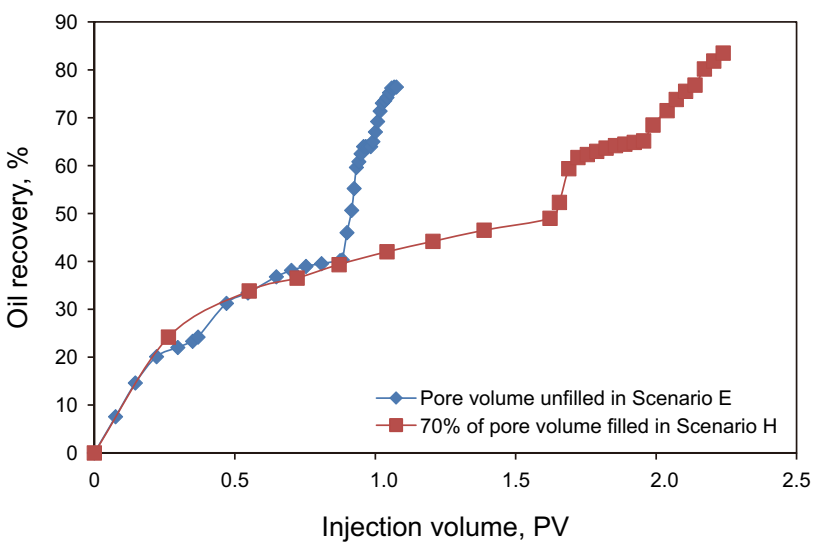

Fig. 17 Comparison of oil recovery of gas-assisted gravity flooding when the pore volume was unfilled in Scenario E and $70 \%$ of pore volume was filled in Scenario $\mathrm{H}$

volume was filled, the flow resistance to injected gas in the lateral direction increased obviously. So, some of injected gas flowed vertically to displace the oil at the lower part of the model. Due to the existence of the filling, the fluid interface became uneven. Besides, as it can be seen from Fig. 17, gas-assisted gravity flooding achieved a much longer production period, and the oil recovery was $7.12 \%$ higher in Scenario $\mathrm{H}$ than that in Scenario E. That indicated the filling in the faults was conducive to gas flooding.

\section{Conclusions}

Based on a two-dimensional physical model of the karst fault system, the fluid flow and production performance of primary gas flooding were discussed, and the effect of gasassisted gravity flooding was examined. The major findings could be concluded as follows.

(1) Compared to water flooding, primary gas flooding could create more flow paths and improve sweep efficiency. A remarkable increment of oil recovery could be achieved in the karst fault system.

(2) During primary gas flooding, gas breakthrough occurred easily because the production well was moved to a higher location after water flooding. The remaining oil distribution was mainly controlled by the developed faults and accumulated in the middle part in a single fault.

(3) The fractures that connected two faults determined the amount of gas that could be stored and the amount of oil that could be displaced in a single fault. Gas injection at a lower location was recommended to delay gas breakthrough during primary gas flooding. 
(4) Gas-assisted gravity flooding could achieve more stable gas-displacing-oil because oil production was at a lower location. The remaining oil accumulated in the area near the injection well and the interwell area after primary gas flooding was mostly recovered.

(5) An energy balance of gas injection and bottom water drive was more conducive to oil production in the karst fault system. For gas-assisted gravity flooding, gas injection at a higher location was recommended to fully take advantage of bottom water drive.

Acknowledgements The authors are highly grateful for the financial support from National Natural Science Foundation of China (51504268) and National Technology Major Project of China (2016ZX05014).

Open Access This article is licensed under a Creative Commons Attribution 4.0 International License, which permits use, sharing, adaptation, distribution and reproduction in any medium or format, as long as you give appropriate credit to the original author(s) and the source, provide a link to the Creative Commons licence, and indicate if changes were made. The images or other third party material in this article are included in the article's Creative Commons licence, unless indicated otherwise in a credit line to the material. If material is not included in the article's Creative Commons licence and your intended use is not permitted by statutory regulation or exceeds the permitted use, you will need to obtain permission directly from the copyright holder. To view a copy of this licence, visit http://creativecommons.org/licenses/by/4.0/.

\section{References}

Akbar M, Vissapragada B, Alghamdi AH, Allen D, Herron M, Carnegie A, et al. A snapshot of carbonate reservoir evaluation. Oilfield Rev. 2000;12(4):20-41.

Chen L, Kang Z, Li P, Rong Y, Dai H. Development characteristics and geological model of ordovician karst carbonate reservoir space in Tahe Oilfield. Geoscience. 2013;27(2):356-65 (in Chinese).

Cruz-Hernández J, Islas-Juárez R, Pérez-Rosales C, Rivas-Gomez S, Pineda-Munoz A, Gonzalez-Guevara JA. Oil displacement by water in fractured vuggy porous media. In: SPE Latin American and Caribbean Petroleum Engineering Conference, 25-28 March, Buenos Aires, Argentina; 2001. https://doi.org/10.2118/69637 -MS.

Deffeyes KS. Hubbert's peak: the impending world oil shortage. New edition. Princeton University Press; 2008.

Hou J, Li H, Jiang Y, Luo M, Zheng Z, Zhang L, et al. Macroscopic three-dimensional physical simulation of water flooding in multiwell fracture-cavity unit. Pet Explor Dev. 2014;41(6):784-9. https ://doi.org/10.1016/S1876-3804(14)60093-8.

Hou J, Luo M, Zhu D. Foam-EOR method in fractured-vuggy carbonate reservoirs: mechanism analysis and injection parameter study. J Pet Sci Eng. 2018;164:546-58. https://doi.org/10.1016/j.petro 1.2018 .01 .057

Hou J, Zheng Z, Song Z, Luo M, Li H, Zhang L, et al. Three-dimensional physical simulation and optimization of water injection of a multi-well fractured-vuggy unit. Pet Sci. 2016;13:259-71. https ://doi.org/10.1007/s12182-016-0079-4.
Jiao F. Significance and prospect of ultra-deep carbonate faultkarst reservoirs in Shunbei area, Tarim Basin. Oil Gas Geol. 2018;39(2):207-16 (in Chinese).

Jin F, Li D, Wang N, Yuan C, Zhao Y, Song W. Influence of different interwell connected pattern on profile control of fracturedcave carbonate reservoir. Sci Technol Rev. 2015;33(24):52-6 (in Chinese).

Kang Z. Principium experiment of oil seepage driven by water in fracture and vug reservoir of carbonate rocks. West China Pet Geosci. 2006;2(1):87-90 (in Chinese).

Li A, Sun Q, Zhang D, Fu S. Oil-water relative permeability and its influencing factors in single fracture-vuggy. J China Univ Pet. 2013;37(3):98-102 (in Chinese).

$\mathrm{Li} \mathrm{S,} \mathrm{Li} \mathrm{Y.} \mathrm{An} \mathrm{experimental} \mathrm{research} \mathrm{on} \mathrm{water} \mathrm{injection} \mathrm{to} \mathrm{replace} \mathrm{the}$ oil in isolated caves in fracture-cavity carbonate rock oilfield. J Southwest Pet Univ (Sci Technol Ed). 2010;32(1):117-20 (in Chinese).

Li Y. The theory and method for development of carbonate fractured-cavity reservoirs in Tahe oilfield. Acta Petrolei Sinica. 2013;34(1):115-21 (in Chinese).

Li Y, Fan Z. Developmental pattern and distribution rule of the fracture-cavity system of Ordovician carbonate reservoirs in the Tahe Oilfield. Acta Petrolei Sinica. 2011;32(1):101-6 (in Chinese).

Li Y, Hou J, Li Y. Fractures and classified hierarchical modeling of carbonate fracture-cavity reservoirs. Pet Explor Dev. 2016a;43(4):655-62. https://doi.org/10.1016/S1876 -3804(16)30076-3.

Li Y, Jin Q, Zhong J, Zou S. Karst zonings and fracture-cave structure characteristics of Ordovician reservoirs in Tahe oilfield, Tarim Basin. Acta Petrolei Sinica. 2016b;37(3):289-98 (in Chinese).

Liu Z, Hou J, Li J, Cheng Q. Study of residual oil in Tahe 4th block fractured heavy oil reservoir. In: North Africa Technical Conference and Exhibition, 20-22 February, Cairo, Egypt; 2012. https ://doi.org/10.2118/151592-MS.

Lu X, He C, Deng G, Bao D. Development features of karst ancient river system in Ordovician reservoirs, Tahe Oil Field. Oil Gas Geol. 2014;36(3):268-74 (in Chinese).

Lu X, Hu W, Wang Y, Li X, Li T, Lyu Y, et al. Characteristics and development practice of fault-karst carbonate reservoirs in Tahe area, Tarim Basin. Oil Gas Geol. 2015;36(3):347-55 (in Chinese).

Lu X, Wang Y, Tian F, Li X, Yang D, Li T, et al. New insights into the carbonate karstic fault system and reservoir formation in the Southern Tahe area of the Tarim Basin. Mar Pet Geol. 2017;86:587-605. https://doi.org/10.1016/j.marpe tgeo.2017.06.023.

Lyu X, Liu Z, Hou J, Lyu T. Mechanism and influencing factors of EOR by $\mathrm{N}_{2}$ injection in fractured-vuggy carbonate reservoirs. J Nat Gas Sci Eng. 2017;40:226-35. https://doi.org/10.1016/j. marpetgeo.2017.06.023.

Manrique EJ, Thomas CP, Ravikiran R, Izadi KM, Lantz M, Romero JL, et al. EOR: current status and opportunities. In: SPE Improved Oil Recovery Symposium, 24-28 April, Tulsa, Oklahoma, USA; 2010. https://doi.org/10.2118/130113-MS.

Qu M, Hou J, Qi P, Zhao F, Ma S, Churchwell L, et al. Experimental study of fluid behaviors from water and nitrogen floods on a 3-D visual fractured-vuggy model. J Pet Sci Eng. 2018;166:871-9. https://doi.org/10.1016/j.petrol.2018.03.007.

Rong Y, Pu W, Zhao J, Li K, Li X, Li X. Experimental research of the tracer characteristic curves for fracture-cave structures in a carbonate oil and gas reservoir. J Nat Gas Sci Eng. 2016;31:417-27. https://doi.org/10.1016/j.jngse.2016.03.048.

Sanchez A, Brown GA, Carvalho VLS, Wray AS, Gutierrez Murillo G. Slickline with fiber-optic distributed temperature monitoring for water-injection and gas lift systems optimization in Mexico. 
In: SPE Latin American and Caribbean Petroleum Engineering Conference, 20-23 June, Rio de Janeiro, Brazil; 2005. https://doi. org/10.2118/94989-MS.

Song Z, Hou J, Liu Z, Zhao F, Huang S, Wang Y, et al. Nitrogen gas flooding for naturally fractured carbonate reservoir: visualisation experiment and numerical simulation. In: SPE Asia Pacific Oil \& Gas Conference and Exhibition, 25-27 October, Perth, Australia; 2016. https://doi.org/10.2118/182479-MS.

Wang J, Liu H, Ning Z, Zhang H, Hong C. Experiments on water flooding in fractured-vuggy cells in fractured-vuggy reservoirs. Pet Explor Dev. 2014;41(1):74-81. https://doi.org/10.1016/S1876 -3804(14)60008-2.

Wang J, Liu H, Xu J, Zhang H. Formation mechanism and distribution law of remaining oil in fracture-cavity reservoir. Pet Explor Dev. 2012;39(5):624-9. https://doi.org/10.1016/S1876-3804(12)60085 -8 .
Wang Y, Hou J, Tang Y, Song Z. Effect of vug filling on oil-displacement efficiency in carbonate fractured-vuggy reservoir by natural bottom-water drive: a conceptual model experiment. J Pet Sci Eng. 2019;174:1113-26. https://doi.org/10.1016/j.petrol.2018.12.014.

Wu G, Li H, Zhang L, Wang C, Zhou B. Reservoir-forming conditions of Ordovician weathering crust in the Maigaiti slope, Tarim Basin, NW China. Pet Explor Dev. 2012;39(2):155-64. https:// doi.org/10.1016/S1876-3804(12)60028-7.

Xu W, Cai Z, Jia Z, Lin Z. The study on ordovician carbonate reservoir karst cavern fillings characterization in Tahe Oilfield. Geoscience. 2010;24(2):287-93 (in Chinese).

Yuan D, Hou J, Song Z, Wang Y, Luo M, Zheng Z. Residual oil distribution characteristic of fractured-cavity carbonate reservoir after water flooding and enhanced oil recovery by $\mathrm{N}_{2}$ flooding of fractured-cavity carbonate reservoir. J Pet Sci Eng. 2015;129:15-22. https://doi.org/10.1016/j.petrol.2015.03.016. 